Studies in English Drama and Poetry

Vol. 3

Monika Sosnowska

University of Łódź

\title{
Sensory Transgression: Literary Representations of Women's Sight and Hearing in William Shakespeare's Hamlet
}

\begin{abstract}
The article focuses on literary representations of women's sight and hearing in William Shakespeare's Hamlet. It firstly addresses the meaning and significance of sensory perception in Western culture. The emphasis is put on the transgressive usage of the senses and the gendering of sensory perceptions which fulfil many cultural functions: determining our cognition, being the tools of power relations or conditioning our sensations. Sensual perception is examined as an unstable cultural construct undergoing changes in time. The textual analysis of Hamlet presents the way in which Ophelia and Gertrude perceive, revealing the manner in which cultural formations of the senses were constructed in Shakespeare's works. Linguistic images of transgressive female perception emerge from a comparison between representations of sensual experience of male and female characters in the play.
\end{abstract}

Introducing sensory studies into the field of cultural studies is a matter of transgression. It is one that has a ground-breaking impact on the apprehension of the senses. Transgression begins when cognitive boundaries are crossed and a disruption in the accepted and conventional approach to the senses arises. Not only does the study of perception belong to natural sciences, but it also arouses interest within broadly defined cultural studies. This concerns especially the "sensual revolution" (Howes, "Introduction" 1) which emerged at the beginning of the twenty-first century and which contributed to recovering perception from the laboratory (4). David Howes explains the heightened contemporary interest in the senses:

The senses are now being investigated by historians, sociologists, anthropologists, geographers and literary scholars among many others. This revolution in the study of the senses is based on the premise that the sensorium is a social construct, which is in turn supported by the growing body of research showing that the senses are lived and understood differently in different cultures and historical periods. ("Charting" 114)

If "the senses are everywhere," literary scholars should examine representations of the senses in works of literature. An important purpose of literary studies would then be to bring to light sensory values encoded in written texts. They are produced and espoused by different groups in society, conveying 
competing cultural paradigms and ideologies. Howes comments on the system of sensory values, explaining that it "is never entirely articulated through language, but it is practiced and experienced (and sometimes challenged), by human beings as culture bearers. The sensory order, in fact, is not just something one sees or hears about; it is something one lives" ("Introduction" 3). Yet a piece of literature consists exclusively of the written word, which is the only trace leading to the encryption of the sensory order of the culture that has generated it. Written texts provide representations of the sensuous dimension of a particular culture, hence they reflect the sensory model and values, (re)created by the lived experience of human beings in certain spatio-temporal conditions. A piece of literature does not allow for an immediate contact with sensory practices and experiences belonging to past times, for the purpose of a written text is to mediate between our contemporary sensual being in the world and a bygone perceptual presence. Through analyses of cultural materials the study of the senses becomes a sensorially-conditioned challenge. As Howes puts it precisely: "Sensorially speaking, the past is a foreign country, and it needs to be explored with senses wide open" ("Can These Dry Bones" 450). William Shakespeare's Hamlet belongs to this foreign country and is also open to scrutiny from the perspective of sensory studies. "The Mona Lisa of literature" has been analyzed with critical attention from various points of view, yet not from the perceptual angle; it has not yet been "sensed."

In his article "Hamlet and the Senses," Mark C. Caldwell makes a suggestion that little attention has been paid to "the imagery of sense" in this drama (157). He highlights "the importance of the five senses to the play," yet concentrates mainly on sight and hearing. In Caldwell's opinion:

Watching and listening, spying and overhearing, are of overwhelming importance in this play. There is a subtle and deliberate emphasis on the five senses, their proper functions, and the physical and spiritual sickness that beset them. (137)

However, he does not directly treat the senses as cultural formations, which is the approach undertaken in my analysis.

According to the contemporary, revolutionary approach to the senses, sensual perception may be understood as an unstable cultural formation undergoing changes over time, that is, "an ever-shifting social and historical construct" (Bull et al. 5). Constance Classen reminds us that

[i]n the West we are accustomed to thinking of perception as a physical rather than a cultural act. The five senses simply gather data about the world. Yet even our time-honored notion of there being five senses is itself a cultural construction. Some cultures recognize more senses, and other cultures fewer. (Worlds of Sense 2) 
Seeing and hearing fulfil many cultural functions, such as determining our cognition, being the tools of power relations, or conditioning our sensations. Both are considered to be the highest senses, among which sight occupies "something of a hegemonic position in Western culture" (M. Smith 19). Consequently, in this culture, vision has ruled the empire of the senses in sensory history in the past centuries. ${ }^{1}$

Hanna Arendt pays attention to the fact that " $[t]$ he predominance of sight is so deeply embedded in Greek speech, and therefore in our conceptual language, that we seldom find any consideration bestowed on it, as though it belonged, among things too obvious to be noticed" (111). With respect to Hamlet, expressions that include the words "eye(s)" and "see" occur in the text 38 and 83 times, respectively. Important words connected with aural perception: "ear(s)" (25 times) and "hear" (58 times), are used with a lesser frequency (Caldwell 140-41). Sense-words, be it in a metaphorical or in a literal sense, appear frequently in the play. The intensified usage of other related expressions, such as "look" and "watch" or "listen," reinforces the significant function of visual and aural perception in the play. Hamlet's sense imagery, on the one hand, has aural and visual perception as an essential source of truth and cognition, while, on the other hand, sight and hearing emerge as deceitful and manipulative informants. As Joan Webber notes:

Sensory images are contemptuous. The play focuses us on the centrality of thought and thought-processes to the human character, and on the abuses of thought and of perception. Eye and ear are traditionally the purest of the human senses, even though easily deceived. Words like "look", "watch", and "see" run like a motif through the play: people use their eyes to observe or spy; they river them upon one another's faces. Pictures, images, playswithin-a-plays are constantly used or discussed; if eyes have grown unseeing, they must be retrained in observation. (86)

Webber also comments on the role of aural perception, claiming that

[e]ars, like eyes, are frequently mentioned. Hamlet Senior was killed by having poison poured into his ears. The ears of the people of Denmark and the court are constantly filled with rumors, with lies and gossip; flattery is a familiar technique. Thus the ear can be incapacitated by false seeming just as the eye can; and the ear can also choose to accept false rumor as the truth. (87)

Both eyes and ears serve as tools of perception either connecting the protagonists with the outer world or disconnecting them from it. This ambiguous attitude towards the senses alternating between confidence and distrust was characteristic of early modern thought.

${ }^{1}$ This is not only because of specific biological facts: human beings primarily experience reality through their eyes, but also because cultural implications of exploring vision surpass the social usage and the role of other senses. 
Despite uncertainties surrounding it, visual perception played a crucial role in the fashioning of the modern conception of the self. Alison Thorne contends that "[i]t is generally accepted that the end of sixteenth century was a crucial moment in the formation of the individual self, a moment when the subject acquired a sharper sense of particularity and its power to shape or 'fashion' its own identity" (104). In Sensory History, Mark M. Smith argues that this modern self aspired to be "a spectator viewing the world, supposedly detached and observing" (23). This understanding of the self entails a quest for both selfknowledge through an inward act of seeing and an examination of the external reality through an outwardly directed act of seeing.

Martin Jay draws conclusions on the modern ocularcentric world, pointing out an extensive range of inventions, such as optical instruments, perspective in art, printing press or surgical practices, which stimulated the eye during the Renaissance and which, afterwards, contributed to visual primacy in the West:

\begin{abstract}
Whether or not one gives greater weight to technical advances or social changes, it is thus evident that the dawn of the modern era was accompanied by the vigorous privileging of vision. From the curious, observant scientist to the exhibitionist, self-displaying courtier, from the private reader of printed books to the painter of perspectival landscapes, from the map-making colonizer of foreign lands to the quantifying businessman guided by instrumental rationality, modern men and women opened their eyes and beheld a world unveiled to their eager gaze. (68)
\end{abstract}

As these inventions coincided with the Renaissance, the early phase of modernity can be described as a time of transition for the purposes of sensory studies. It may be regarded as a liminal and, therefore, transgressive period when crucial perception-related changes occurred, specifically the transition from an acoustically-orientated reality towards a visually-embedded perception of the world. If one considers McLuhan's notion that every culture generates and acts according to an "order of sensory preferences" (241), then Shakespeare's times escape any rigid classification. A disruption in the sensory order, a suspension of the hierarchy between the senses and the emergence of subversive values characterize the early modern period, unable to privilege either the eye or the ear.

Bruce R. Smith's pronouncement that " $[\mathrm{k}]$ nowing the world through sound is fundamentally different from knowing the world through vision" (129) provokes us to ruminate on the process of the acquisition of knowledge as well as some pivotal functions of hearing in Western culture. ${ }^{2}$ As a cultural formation, the sense of hearing has been associated with several rudimentary meanings in the West. One of the references attributed to the ear pertains to its vulnerability, particularly it being "always in operation, unreflectively

${ }^{2}$ Aural perception cannot be equal to visual perception if judged by the intensity of academic research on hearing. Mark M. Smith believes it is high time scholars challenged "their deafness to the aural worlds of the past" (137). 
accumulative, and naively open to even the most harmful of loud, high or concussive sounds" (Schwartz 487). Absorbing uninvited sounds that are elusive in their nature, the ear is traditionally considered to be not as reliable a source of knowledge as the eye. In identifying truth and objectivity and capturing events, the status of hearing comes a poor second when compared to seeing. In aural/oral cultures, especially before modernity, people had confidence in sounds pre-eminently in the form of storytelling and everyday speech. Yet the transgressive time was about to appear with the early modern transition, embracing perceptive values and practices, and bringing changes into the sensory order. With respect to the sensual past, transgression touches upon the revolutionary shift in cultural paradigms, based on the revaluation of the role of the senses and subversion of the sensory hierarchy. Such an overthrowing of the established order initiates a metamorphosis of the sensory order: gradually from the world immersed in aural/oral practices into a visually-dependent reality. ${ }^{3}$ Since early modern "eyes and ears" encountered entirely different images and sounds in comparison to contemporary perception, the representation of seeing and hearing is encoded in cultural materials through and with sensory ciphers of the past.

The transgressive character of early modern society - uncertain about the "nature" of its sensual experiences - becomes "visible and audible" on the textual level of Hamlet. Literary representations of sensory experiences in the play allow one to examine female ways of perceiving in Shakespeare's times. It is possible to analyze the cultural construction of sensory perception and its reflection in the play through the examination of sensorially-imbued passages of the text, while simultaneously putting them into the broader context of Shakespeare's times. Rembowska-Płuciennik draws attention to the "mutual sensual perception" occurring between any fictional characters (338). She is of the opinion that in a literary text particular "states of the observee" may be identified; they allow for an "insight into the other" (339). Apparently, "the other" emerging from the dialogues is either a male or female protagonist. Curiously enough, the first scene of the play indicates that "there is something wrong with sensory perception," leading each character astray and providing blurred visions or indistinct sounds. In the opening words of the play, Bernardo directs his question "Who's there?" into the night-time void. Bernardo seems to be surrounded by darkness and deafness, which hinders his ability to see an approaching person clearly or recognize his or her voice from a distance. Caldwell summarizes the essence of the play in a few sentences, pointing out the dramatic strategy based on references pertaining to the eyes or ears:

${ }^{3}$ As the case in point, Hamlet shows how the tension between two "rational" senses arose in the early modern period. Sensory imagery of the play brings up the issue related to the Renaissance "wrestling between sight and hearing." These two senses compete as organs of perception for the mastery of the empire of the senses. 
It opens with Barnardo and Francisco watching for the Ghost. We then shift to Gertrude and Claudius in council, watched by the ostentatiously silent Hamlet, who, summoned outside by Horatio and Marcellus, himself joins the vigil. When the Ghost reappears, Horatio and Marcellus follow, carefully observing the meeting. Polonius hatches the plot to spy on Hamlet: "at each eat a hearer" (2.2.388-89). Hamlet devises the plot to stage a play to be watched by Gertrude and Claudius, while he and Horatio in turn watch them. After the mousetrap is sprung, Hamlet watches Claudius at prayer and is in turn overheard by Polonius during the closet scene. In the company of Rosencrantz and Guildenstern, Hamlet then watches Fortinbras' army cross the stage. Immediately thereafter we see Horatio, Gertrude, and Claudius observing, but doing nothing about, the mad Ophelia. Hamlet returns from the voyage to watch Ophelia's funeral procession; Claudius and Gertrude watch while Hamlet and Laertes struggle in the grave; and finally, in an ironic parody both of these scene and the play-within-a-play, Claudius arranges to watch a performance, the mock duel between Hamlet and Laertes, from which the bloody and precipitous denouement follows. (138)

With their eyes and ears wide open, all Shakespeare's characters are portrayed as sensorially interacting with each other and the mysterious surroundings of Elsinore.

Ophelia's and Gertrude's experiences through their senses differ from those of the male characters in the play. The sensory code which delineates boundaries of human perception, like many other cultural codes, deprives the female characters of their own audition and vision. Both Ophelia and Gertrude are portrayed as breaking the rules that exist in Renaissance society by perceptual transgression. Representations of women's sight and hearing form a sensory minority. Although presented from Shakespeare's, and thus a male, point of view, marginal sensory experiences of Ophelia and Gertrude become a potential source of information about cultural constructions of the senses in early modern times. It is perhaps worth mentioning here that gendering of visual and aural perception in the transitional Shakespearean era prevents the human sensorium from being universalized and ahistoricized. A gender-based distinction of sensory perception assumes that each of the senses has either feminine or masculine inclinations. Such a distinction was popular and prevailed in premodernity.

Constance Classen investigates how "the senses are inflected with gender values" (Color 63). She also distinguishes how meanings attributed to the cultural constructions of the senses and gender produce specific links (in other words, new cultural formations) between each sense and either masculinity or femininity, for instance, the "male gaze" and the "female touch." According to Classen:

Women have traditionally been associated with the senses in Western culture, and in particular, with the "lower" senses. Women are forbidden taste, the mysterious smell, the dangerous touch. Men, by contrast, have been associated with reason, as opposed to the senses, or else with sight and hearing as the most "rational" of the senses. The occultation 
of the sensory underpinnings of Western culture by the modern visual and rational world view may therefore be read as an occultation of certain feminine dimensions of that culture. (Color 2)

This quotation, in which hearing and sight are presented at the top of the hierarchy of the senses, demonstrates that the significance of aural and visual perception contributes to the marginalization of other sensory receivers and transmitters. The sensory code of Hamlet - which is manifested through the use of expressions that evoke any of the senses - reveals how elevating or downplaying of sensory perception by Shakespeare may reflect social meanings added to the senses. The eclipse of feminine sensory values contributed to the underpinning of the patriarchal system in Western culture, but simultaneously a reversal within the hierarchy of the senses in the early modern culture left some space for women's particular manner of seeing and hearing. This space opens up possibilities for subversive perceptual behaviour, violating the rational/masculine usage of the sense of sight and hearing.

Along with the idea of gendering of the senses came the modern concept of the disembodied self. Since Hamlet is a liminal play, suspended between a premodern understanding of sensory perception and the modern cultural approach to the senses, it also reflects the clash between a "unifying" pre-Cartesian and a "separating" Cartesian paradigm of subjectivity. The latter was practically just emerging at the time and its reflection in the text of the play was rather more of an intellectual prediction of "things to come" made by Shakespeare than an actual mimesis of a deep-seated philosophical thought of the period. The shift in the comprehension of the self coincided with and influenced the change in the interpretation of the sense of vision. The emerging model of subjectivity dichotomized the body and the mind, and divided the self into corporeal and rational parts. This dualistic notion of the self embraced the empire of the senses, affecting sight by discovering the split within visual perception. Seeing functions in two dimensions: the inward - as a source of perception of the mind, or the outward - passively operating as a channel, providing stimuli from the outside. It is vision that is deployed in Hamlet to signal the transition in the conceptualization of the self as well as its resonance in "splitting of the eye" between the mind and the body.

Seeing with the mind's eye is presented in Hamlet as the male privilege connected with having the power to investigate and speculate, constructing knowledge about the world, being a reliable eye-witness and an active perceptual participant whereas the corporeal eye, which symbolically expresses women's sight, is characterized by the biological attribute of accepting external stimuli, passivity and therefore the inability to transform observation into knowledge. Manifestation on the textual level of the play that representations of visual perception in Hamlet differentiate in respect to gender connects sensory 
imagery of the play with gender symbolism underlying early modern culture. Undoubtedly visual perception may be exploited by each gender. Making use of the masculine sense to some extent deprived women of their perspective and limited their ability to use sight in rational and contemplative ways as men did. Classen contends that

[i]n the case of each sense, men would typically be associated with what were thought to be the nobler qualities of that sense, and women with the more ignoble. As regards sight, for example, men were ideally imagined to employ this sense for intellectual activities such as studying, while women made use of it for the sensual ends of acquiring gaudy clothes and admiring themselves in the mirror. Similarly, men were imagined to use the sense of hearing to listen to weighty discourses, while women employed their hearing to attend to frivolous gossip and love talk. (Color 66)

Early modern perceptual paradigms accorded with the strictly patriarchal demands of society in which women's transgression was too portentous for recognizable standards of femininity. The culture of the transitional Shakespearean era considered specific sensory behaviours as transgressive, e.g., rational exercise of the senses by women. Therefore, how women "should use" their eyes and ears was of particular interest to society. Limited in their "perceptual field" of existence, through perceptive subversiveness, women in Hamlet appear to express their anger and to protest against cultural confinements imposed on them.

Violation of the established modes of sensing by women becomes evident in the form of significant textual interruptions, that is to say, representations of transgressive acts of perception in the play. A case in point may be Ophelia's metamorphosis from a submissive daughter and sister taking the perspective of men (or being forced to internalize such mode of perceiving) to a madwoman creating her own illuminating visions. Although throughout the play Ophelia is being manipulated by her father, brother and even Hamlet, who attempt to impose their point of view on her perspective, she finds perceptual freedom in insanity. The submissiveness of the corporeal eye becomes clear when, for example, Polonius rebukes his daughter for being too naïve in believing Hamlet's declarations of love. Ophelia is left with pure observations but not allowed to transform them into confirming knowledge. When the father asks her: "Do you believe his 'tenders', as you call them?" (1.3.102), Ophelia replies: "I do not know, my lord, what should I think" (1.3.103). Perhaps the bombardment with too many images and representations of womanhood - produced by men cause mental chaos that engenders Ophelia's madness. Yet it is not until she loses her mind that she experiences the sensory transgression. With her somatic eyes boring into nothingness, Ophelia pours out the excess of the images anchored in her mind's eye through prophetic speeches and songs of an 
abandoned lover. Her visions seem to go beyond the imagination of the viewers witnessing the "spectacle of insanity."

In the same scene of madness, hearing is also portrayed as a sense which is used by Ophelia in a subversive manner. Nowhere is it more evidently manifested than through the lines working to show the inattentive audition of the madwoman, focused on the voices in her head. Ophelia offers ambiguous answers to those who interrupt her nonsensical speeches or bawdy songs. To the Queen's question: "Alas, sweet lady, what imports this song?" she responds: "Say you? Nay, pray you, mark" (4.5.27-28) as if she is not paying attention to what has been said. By subverting the role of a woman as a passive hearer, she (un)consciously employs her hearing to "shut her ears" to unwanted words uttered by others. The refusal to take notice of sounds directed at her attests to crossing sensory boundaries. It leads to finding one's own voice regardless of the voices that try to reach Ophelia. Contrastingly, before Ophelia takes leave of her senses, her depiction by Shakespeare suggests that she is the "blind" eyewitness and "voiceless" hearer, left with pure visual and aural sensations but not allowed to transform them into rational understanding. Ophelia's reflections and judgments become shaped and verified by Polonius' and Laertes' opinions, that is to say, by their incorporeal eye. Under the watchful gaze of men, Ophelia becomes powerless in speech and vision. Empowered by "altered states of perception," the woman openly expresses her standpoint by drawing mental pictures that "would make one think there might be thought" (4.5.12) and pours "the poison of deep grief" (4.5.81) into the "ears" of the Elsinore court.

Another example of the transgressive female character in the play is the sensually and sexually subversive Queen Gertrude. Although the eyes of a mourner should be closed to physical attractiveness of the male body while the ears should resist any verbal temptation, for instance, men's seductive voices or erotic allusions, Gertrude shortens the period of grieving by remarrying her dead husband's brother. She does not properly fulfil the role of a mourning widow and, as she hastily remarries, she rejects expectations surrounding a woman who has lost her husband. However, this refusal cannot be treated as a conscious transgression since Gertrude does not remain an independent woman. The Queen acts as if she was blinded in a literal and figurative sense of the word, as if she was led astray by her eyes, which made her vision function defectively and therefore unable to detect that her husband's murderer was his brother. Gertrude non-cogitatively absorbs seductive images from the outside world and yields her perspective to Claudius' worldview. The symbolic attributes of the female somatic eye, such as submissiveness or disempowerment of independent judgment, become evident when Gertrude takes the perspective of her second husband. 
Gertrude's improper response to the mourning period results in verbal criticism from Hamlet, who enumerates the stages she should go through after the loss of her husband. Instead of performing the role of the widow, manifesting her sorrow through "windy suspiration of forced breath," "the fruitful river in the eye" and "the dejected haviour of the visage" (1.2.79-81), Gertrude opens her senses to the visual and aural attractions of her second marriage. In a pivotal scene of the play, during Gertrude's encounter with Hamlet in her closet, two gendered ways of perceiving are contrasted. The Queen's visual perception dominated by the somatic eye is set in opposition to Hamlet's activation of his mind's eye. The gendering of the eye is revealed through the dialogue which prioritizes Hamlet's masculinized point of view. He endeavours to enlighten his mother about King Hamlet's death. Unable to believe that Gertrude chose Claudius as her second husband, Hamlet uses a picture contrasting his father with his uncle: "Here is your husband like a mildewed ear / Blasting his wholesome brother" (3.4.62-63). Hamlet takes advantage of being allowed by culture to express male supremacy over women by aggressively interrogating his mother: "Have you eyes?" (3.4.63) and aiming to undermine the reliability in Gertrude's visual perception.

Hearing is in the case of Gertrude mostly employed to listen to opinions given by Claudius, which places her under control of male voices. As the plot reveals, the Queen either appears alongside Claudius or faces his entrance in each act. This textual strategy imposed by Shakespeare may imply that Gertrude's audition is exposed to male speeches, which results in abating her voice and weakening the power to affect men's hearing. Although she has maternal power over her son, she seems to be ignored by not being obeyed. She meets with violent, abusive and ear-piercing words uttered by Hamlet, intending to drown out the audibility of Gertrude's voice, especially in the closet scene. Her verbal reactions are mostly provoked by Hamlet's offensive manner of speaking.

It should be stated here that ultimately the Queen also transgressively exploits visual perception in order to trespass its passivity and fleshiness. Firstly, Shakespeare portrays Gertrude as a person who becomes enchanted by what her bodily eyes communicate about the world outside and follows the passionate scopic drive, which leads her into "incestuous sheets." What constitutes Gertrude's transgression is her refusal to obey the command of Claudius in the final scene of the play when an opportunity to exploit audition subversively appears. The Queen negatively responds to Claudius' command that she should not drink from the cup and she decides to produce knowledge independently of any masculine point of view. Before she dies, after drinking the poisonous drink, her eyes meaningfully express her motherly love for Hamlet and disappointment with her relation with men. She willingly activates her mind's eye to speculate 
and reflect on the events taking place in Elsinore. Gertrude passes away as a transgressive character who crossed boundaries of women's perception.

It is apparent that Shakespeare was not sensorially indifferent. Representations of sight and hearing are deployed in Hamlet to highlight their masculine attributes and reflect sensory preferences of the early modern period. Gendering of the sensory experience in Hamlet pertains to the textual coding of the play. Linguistic images of transgressive female perception emerge from juxtaposing them with depictions showing male sensory experience. Analyzing early modern distinctions in sensing between men and women demonstrates that pivotal gender differences and inequalities in accessibility and exploitation of the senses existed. Sensorially symbolized gender has a specific code referring to the ways in which men and women use their senses in social life. The ear and the eye are significant cultural carriers for the Renaissance period, conveying metaphorical and literal meanings. Transgression that occurred in Shakespeare's times revealed that "[t]he way a society senses is the way it understands" (Classen, "McLuhan" 161). Not only did Shakespeare portray early modern society's suspension between two modes of sensing, and thus thinking, but he also created gendered representations of sight and hearing which become "visible and audible" on the textual level of Hamlet.

\section{Works Cited}

Arendt, Hanna. The Life of the Mind. Ed. Mary McCarthy. One-volume ed. New York: Harcourt Brace Jovanovich, 1987. Print.

Bull, Michael, et al. "Introducing Sensory Studies." Senses and Society 1.1 (Mar. 2006): 5-7. Print.

Caldwell, Mark L. "Hamlet and the Senses." Modern Language Quarterly 40 (1979): 135-54. Print.

Classen, Constance. The Color of Angels. Cosmology, Gender and the Aesthetic Imagination. New York: Routledge. 1998. Print.

---. "McLuhan in the Rainforest: The Sensory Worlds of Oral Cultures." Empire of the Senses: The Sensual Culture Reader. Ed. David Howes. Oxford: Berg, 2004. 147-63. Print.

---. Worlds of Sense: Exploring the Senses in History and Across Cultures. New York: Routledge, 1993. Print.

Howes, David. "Can These Dry Bones Live? An Anthropological Approach to the History of the Senses." Journal of American History (Sept. 2008): 442-51. Print.

---. "Charting the Sensorial Revolution." Senses and Society 1.1 (Mar. 2006): 113-28. Print.

---. "Introduction: Empires of the Senses." Empire of the Senses: The Sensual Culture Reader. Ed. Howes. Oxford: Berg, 2004. 1-20. Print

Jay, Martin. Downcast Eyes: The Denigration of Vision in Twentieth-Century French Thought. California: University of California Press, 1994. Print.

McLuhan, Eric, and Frank Zingrone, eds. Essential McLuhan. New York: Basic Books, 1995. Print. 
Rembowska-Płuciennik, Magdalena. Poetyka i antropologia. Cykl podolski Włodzimierza Odojewskiego. Kraków: Universitas, 2004. Print.

Schwartz, Hillel. "The Indefensible Ear. The History." The Auditory Reader. Ed. Michael Bull and Les Back. Oxford: Berg, 2004. 487-502. Print.

Shakespeare, William. Hamlet. Ed. Ann Thompson and Neil Taylor. London: Thomson Learning, 2006. Print. Arden Shakespeare. Third Series

Smith, Bruce R. "Tuning into London c. 1600." The Auditory Reader. Ed. Michael Bull and Les Back. Oxford: Berg, 2004. 127-36. Print.

Smith, Mark M. "Listening to the Heard Worlds of Antebellum America." The Auditory Reader. Ed. Michael Bull and Les Back. Oxford: Berg, 2004. 137-64. Print.

---. Sensory History. Oxford: Berg, 2007. Print.

Thorne, Alison. Vision and Rhetoric in Shakespeare: Looking Through Language. Houndmills: Macmillan Press, 2003. Print.

Webber, Joan. "Hamlet and the Freeing of the Mind." English Renaissance Drama. Essays in Honor of Madeleine Doran and Mark Eccles. Ed. Standish Henning, Robert Kimbrough, and Richards Knowles. Carbondale: Southern Illinois University Press, 1976. 76-100. Print. 